\title{
Tuber Yield and Stability Assessment of Potato Genotypes in Bangladesh
}

M.N. Amin, M.M. Rahman, S. Naznin, M.K. Alam, M.M.H. Tipu, M.Z.H. Prodhan, M.M. Islam, B.C. Kundu

10.18805/IJARe.A-607

\begin{abstract}
Background: Scarcity of improved cultivars with wide adaptability and stability in tuber yield is one of the most important reasons for poor yield of potato in Bangladesh. The stable cultivars which perform well over a wide range of environments become very important for farmers and processors because they require reliable production and quality. The current study was aimed to evaluate 10 potato genotypes (eight BARI released cultivars and two advanced clones) grown in six regions to find high yielding and stable performing genotypes.

Methods: Ten potato genotypes were evaluated at six locations of Bangladesh during season 2017-2018 following a randomized complete block design with three replications. The potato genotypes were sown on $15^{\text {th }}$ November 2017 . Fertilizer doses, irrigation, plant protection, weeding, earthing up and other agronomic practices were applied according to Tuber Crops Research Center (TCRC), Bangladesh Agricultural Research Institute (BARI) recommendation. Plant height, canopy coverage, stems per hill, tubers per hill, marketable and non-marketable tuber yield at 65 days and at 90 days, tuber weight and dry matter (\%) were recorded respectively.

Result: Additive Main effect and Multiplicative Interaction (AMMI), genotype and genotype $x$ environment interaction (GGE) bi-plot analysis revealed that environment and genotype effects were highly significant. AMMI and GGE bi-plot illustrated that environments were diverse and variation among genotypes were found. Considering yield and yield contributing characters, BARI Alu-91 (Carolus) and BARI Alu-25 (Asterix) showed higher yield without further influenced by environment. BARI Alu-89 (Fortus), Clone 12.2 and Colomba had better mean performance with more adaptability and stability.
\end{abstract}

Key words: AMMI, Bi-plot, Genotypes, GGE, Yield.

\section{INTRODUCTION}

Potato is one of the important food in the world which supplies important nutrients to the human diet considered as a non-fattening, nutritious and wholesome food (Kumari et al., 2018). Furthermore, Potato produces more dry matter and protein per hectare than the other cereal crops (Kumari et al., 2018; de Haan and Rodriguez, 2016). The improvement of potato yield per unit area and full production capacity is an important way of solving problems related to food security in Bangladesh. so increasing potato yield per unit area is one of the essential way of ensuring the stability of the potato yield (Wang et al., 2018) and (Lei et al., 2016).

Scarcity of improved cultivars with wide adaptability and stability in tuber yield is one of the most important reasons for poor yield of potato in Bangladesh. Global climate change is expected to cause disturbance in most agricultural production including potato cultivation (Hijmans, 2003). Major cultural adaptations involving planting time and cultivar choice will need to be applied to mitigate the impact of increased temperatures (Hijmans, 2003). The stable cultivars which perform well over a wide range of environments become very important for farmers and processors because they require reliable production and quality. Additive Main Effects and Multiplicative Interaction (AMMI) analysis predicts adaptation and stability of cultivars and involves both additive and
Breeder Seed Production Centre, Bangladesh Agricultural Research Institute, Debiganj, Panchagarh-5020, Bangladesh.

Corresponding Author: M.N. Amin, Breeder Seed Production Centre, Bangladesh Agricultural Research Institute, Debiganj, Panchagarh-5020, Bangladesh. Email: nurul01141@yahoo.com

How to cite this article: Amin, M.N., Rahman, M.M. Naznin, S., Alam, M.K., Tipu, M.M.H., Prodhan, M.Z.H., Islam, M.M. and Kundu, B.C. (2021). Tuber Yield and Stability Assessment of Potato Genotypes in Bangladesh. Indian Journal of Agricultural Research. 55(5): 609-613. DOI: 10.18805/IJARe.A-607.

Submitted: 28-10-2020 Accepted: 13-03-2021 Online: 21-08-2021

multiplicative components of two way data structure (Mahalingam et al., 2006). Breeders can predict genotypic potentiality and environmental influences precisely using this model.

AMMI model is used to calculate complex GEI, stability indices and consider the mean trait performance over all environments and GGE bi-plot can find mega-environments as a cluster of environments which provide similar rankings for genotypes within a region (Yan et al., 2007). The objective of this study was to evaluate 10 potato genotypes (eight BARI released cultivars and two advanced clones) grown in six regions for tuber yield using AMMI and GGE statistical models. 
Tuber Yield and Stability Assessment of Potato Genotypes in Bangladesh

\section{MATERIALS AND METHODS}

Six genotypes of potato Colomba, Zinared, Clone 12.2, BARI Alu-86 (12.13), BARI Alu-89 (Fortus), late blight resistant BARI Alu-90 (Alouette) and late blight resistant BARI Alu91 (Carolus) along with BARI Alu-7 (Diamant), BARI Alu-29 (Courage), BARI Alu-28 (L. Rosetta) and BARI Alu-25 (Asterix) as checks were evaluated during 2017-18 at six locations, viz., Munshiganj, Bogura, Jassore, Jamalpur, Gazipur and Debiganj in Randomized Complete Block design with three replications in plot size was $3 \mathrm{~m} \times 3 \mathrm{~m}$. Whole tubers (BSPC, Debiganj source) planted with a spacing of $60 \mathrm{~cm} \times 25 \mathrm{~cm}$, during November 20-25, 2017 . Fertilizers were applied @ 325-220-250-120 kg/ha of urea, TSP, MOP and gypsum, respectively. Recommended intercultural operations were done. The crop was harvested at full maturity. Data were taken on plant height $(\mathrm{cm})(\mathrm{PH})$, Stem number per hill $(\mathrm{SNH})$, tuber number per hill $(\mathrm{TNH})$, Yield (t/ha) at 65 Days (Y65), Yield (t/ha) at 95 Days (Y95), tuber weight (t/ha) per hill (TWH), dry matter (DM). AMMI stability value (ASV) was estimated at 65 days and 95 days. All data were processed and analyzed using AMMI model (Agricolae) software $\mathrm{R} \times$ 64-program version 3.3.2 and PB Tools. Data across sites were pooled and combined analyses of variance for stability were done following Singh and Chowdhury (1976). Stability parameters i.e., the regression coefficient (bi) and deviation from regression ( $\mathrm{S}^{2} \mathrm{di}$ ) were estimated according to Eberhert and Russel (1966). AMMI Stability value was estimated following Purchase et al. (2000) using Crop Stat program. The temperature variation and average relative humidity was measured using HoBoware (http://www.onsetcomp.com. The locations were Bogura $\left(24.78^{\circ} \mathrm{N}, 89.35^{\circ} \mathrm{E}\right)$; Jashore $\left(23.17^{\circ} \mathrm{N}, 89.18^{\circ} \mathrm{E}\right)$; Jamalpur $\left(28.92^{\circ} \mathrm{N}, 89.96^{\circ} \mathrm{E}\right)$; Mushiganj $\left(23.23^{\circ} \mathrm{N}-90.10^{\circ} \mathrm{E}\right)$; Debiganj $\left(26.27^{\circ} \mathrm{N}-88.45^{\circ} \mathrm{E}\right)$ and Gazipur $\left(24.36^{\circ} \mathrm{N}-88.66^{\circ} \mathrm{E}\right)$. The climatic conditions in the potato growing regions (2017-18) were favorable for cultivation with average relative humidity $57 \%$ and average highest temperature of $30.5^{\circ} \mathrm{C}$ and average lowest temperature $20^{\circ} \mathrm{C}$.

\section{RESULTS AND DISCUSSION}

The significant interaction effect was observed for all the genotypes and the different growing locations (Table 1). The mean sum of square for the genotypes and environments were significant all the traits (Table 1). indicating the presence of genetic variability in the materials and diversity of the environments. A major part of deviation in tuber yield and yield contributing characters resulted from location variation.

The tallest plant $(82.2 \mathrm{~cm})$ was found in BARI Alu- 86 (12.13) and the lowest plant height $(55.2 \mathrm{~cm})$ was found in the genotype Zinared. The highest number of stem/hill (6.4) was exhibited by genotype BARI Alu-89 (Fortus) while the lowest (4.5) from BARI Alu-28 (L. Rosetta). The highest number of tubers per hill (11.2) was recorded from the genotype BARI Alu-86 (12.13) and the lowest number of tubers per hill (6.7) was observed from the genotype BARI Alu-25(Asterix) (Table 2).

Marketable Tuber yield at 65 DAP was recorded to identify the early bulker genotypes. The highest 65 DAP yield was found (24.31 t/ha) with the genotype BARI Alu-86

Table 1: Combine variance analysis of yield trait of potato germplasm in six locations sites.

\begin{tabular}{|c|c|c|c|c|c|c|c|}
\hline Parameter & $\mathrm{PH}$ & $\mathrm{SNH}$ & $\mathrm{TNH}$ & Y65 & Y95 & TWH & DM \\
\hline Rep within Loc & 32.14 & 1.10 & 3.06 & $32.04^{*}$ & 30.26 & 0.01 & $7.51^{*}$ \\
\hline Loc $(E)$ & $2564.13^{* * *}$ & $57.72^{* * *}$ & $74.56^{* * *}$ & $986.91^{* * *}$ & $1225.92^{* * *}$ & $0.20^{* * *}$ & $142.03^{* * *}$ \\
\hline Genotype (G) & $1332.89^{* * *}$ & $9.44^{* * *}$ & $42.59^{\star * *}$ & $133.41^{* * *}$ & $614.34^{\star * *}$ & $0.15^{* * *}$ & $48.03^{* * *}$ \\
\hline$E \times G$ & $178.51^{\star * *}$ & $2.33^{* * *}$ & $5.52^{* * *}$ & $30.83^{* * *}$ & $84.98^{* \star *}$ & $0.02^{* * *}$ & $8.12^{* * *}$ \\
\hline Residuals & 18.51 & 0.82 & 1.84 & 14.59 & 21.85 & 0.01 & 3.48 \\
\hline
\end{tabular}

${ }^{\star \star \star}$ Significant at the 0.01 probability level.

Table 2: Mean value for yield and yield attributing traits of potato genotypes across six locations.

\begin{tabular}{|c|c|c|c|c|c|c|c|c|c|}
\hline Genotypes & $\mathrm{PH}$ & $\mathrm{SNH}$ & $\mathrm{TNH}$ & TWH & DM & Y65 & Y95 & 65ASV & 95ASV \\
\hline BARI Alu-7 (Diamant) & 59.69 & 6.20 & 7.55 & 0.45 & 21.32 & 17.68 & 27.67 & 7.10 & 3.80 \\
\hline BARI Alu-25 (Asterix) & 64.29 & 5.81 & 6.74 & 0.40 & 19.38 & 17.17 & 23.2 & 1.34 & 1.12 \\
\hline BARI Alu-28 (L. Rosetta) & 55.8 & 4.47 & 7.20 & 0.40 & 23.10 & 17.95 & 24.85 & 0.67 & 1.62 \\
\hline BARI Alu-89 (Fortus) & 55.82 & 6.41 & 8.60 & 0.52 & 18.60 & 23.42 & 31.58 & 1.40 & 0.75 \\
\hline BARI Alu-86 (12.13) & 82.23 & 6.38 & 11.22 & 0.69 & 17.94 & 24.31 & 42.32 & 1.92 & 3.93 \\
\hline BARI Alu-90 (Alouette) & 63.51 & 5.10 & 7.73 & 0.49 & 19.09 & 21.47 & 29.81 & 3.89 & 1.59 \\
\hline BARI Alu-91 (Carolus) & 58.91 & 5.58 & 7.97 & 0.42 & 18.56 & 16.90 & 24.42 & 5.40 & 3.91 \\
\hline Colomba & 62.32 & 5.22 & 8.69 & 0.53 & 18.06 & 21.72 & 30.84 & 3.58 & 2.36 \\
\hline Zinared & 55.24 & 4.53 & 6.80 & 0.52 & 18.38 & 20.46 & 30.84 & 2.92 & 1.18 \\
\hline Clone 12.2 & 73.19 & 4.96 & 10.66 & 0.61 & 20.00 & 18.00 & 36.52 & 0.22 & 3.24 \\
\hline CV & 12.7 & 20.20 & 20.40 & 19.5 & 11.50 & 22.3 & 21.0 & - & - \\
\hline LSD & 5.25 & 0.72 & 1.11 & 0.06 & 1.48 & 2.92 & 4.17 & - & - \\
\hline Means & 63.14 & 5.458 & 8.32 & 0.50 & 19.43 & 19.91 & 30.2 & - & - \\
\hline
\end{tabular}


(12.13), whereas the lowest value 16.9 t/ha was found from the BARI Alu-91 (Carolus). On the other hand, the highest marketable tuber yield at 95 DAP was found (42.3 t/ha) with the genotype BARI Alu-86 (12.13) followed by clone 12.2 (36.5 t/ha) (Fig 2) whereas the lowest value $23.2 \mathrm{t} /$ ha was found from the genotype BARI Alu-25 (Asterix) (Table 2). The highest tuber weight per hill $(0.68 \mathrm{~kg})$ was observed in BARI Alu-86 (12.13) followed by clone $12.2(0.6 \mathrm{~kg})$ and the lowest tuber weight per hill was found in BARI Alu-25 (Asterix) which is $0.4 \mathrm{~kg}$. The highest percent dry matter was found in BARI Alu-28 (L. Rosetta) (23.1\%) followed by BARI Alu-7 (Diamant) $(21.3 \%)$ and lowest was found in BARI Alu-86 (12.13) (17.9\%) (Table 2).

\section{General and specific genotypic adaptation}

AMMI and GGE biplot explained the genotypic adaptation or stability among genotypes. In the AMMI 1 biplot, the displacements along the abscissa indicate differences in main (additive) effects, whereas displacements along the ordinate indicate differences in interaction effects. The relative ranking of different genotypes on the biplots is based on its projection on to the XY-axis in AMMI biplot. Although the measured yield is a combined outcome of the effects of the genotype $(G)$, $E$ and $G E$ interaction, only $G$ and $G \times E$ are relevant to cultivar evaluation and mega environment identification. Typically, E explains mostly ( $80 \%$ or higher) of the total yield variation, while $G$ and $G E$ are usually small (Yan and Kang, 2002). Fig 1 showed that the genotypes which are in the right side of perpendicular potato genotypes The BARI Alu-86 and clone 12.2 are less affected by $\mathrm{G} \times \mathrm{E}$ inter action (Fig 1). The more the PC1 scores approximate to zero, the more stable the genotypes i.e. BARI Alu 25, BARI Alu-89, BARI Alu-28 among the environments under study (Fig 1). Genotypes and environments positioned close to each other in the biplot have positive associations, thus these enable the creation of agronomic zones with relative ease. The BARI Alu-86 and clone 12.2 had a specific adaptation to Gazipur, BARI Alu-7, BARI Alu-90to Munshiganj whereas BARI Alu-91, BARI Alu-25 adapted to Debiganj and BARI Alu-89, Colomba, BARI Alu-28 ( $L$. Rosetta) to Bogura (Fig 1). AMMI Stability value was presented in Table 2.

\section{Selection of adaptive potato genotype based on GGE biplot}

There are six sectors with BARI Alu-7, BARI Alu-86, Clone 12.2, Colomba, BARI Alu-91, BARI Alu-25 as the peak genotype and has two environment sectors: sector 1 (Debiganj, Munshiganj, Jassore and Jamalpur) and sector 2 (Gazipur and Bogura) (Fig 3). Genotypes BARI Alu-86 are stable in four sites (sector 1). BARI Alu-89 and Clone 12.2 adapts well to sector 1 (Fig 3).

Regression coefficient (bi) was considered as a parameter of response of the genotype to different environment. In addition, deviation from regression $\left(S^{2} \mathrm{di}\right)$ was used as the index of stability. Stability parameter i.e. regression coefficient (bi) and deviation from regression
$\left(\mathrm{S}^{2} \mathrm{di}\right)$ of the individual genotypes for plant height, stem per hill, tuber per hill, marketable tuber yield at 65 days and at 90 days respectively, tuber weight, dry matter (\%) are presented in Table 3. A relatively lower value of bi (close to 1) will mean less responsive to the environmental change, which state more adaptive variety.

Plant height, stem per hill, tuber per hill, tuber weight, dry matter (\%) are important characters which play a significant role in varietal selection. Similarly, Houghland et al. (1961), Cole (1980) and Munzert (1987), showed the positive correlation between late maturity, tuber size, plant growth

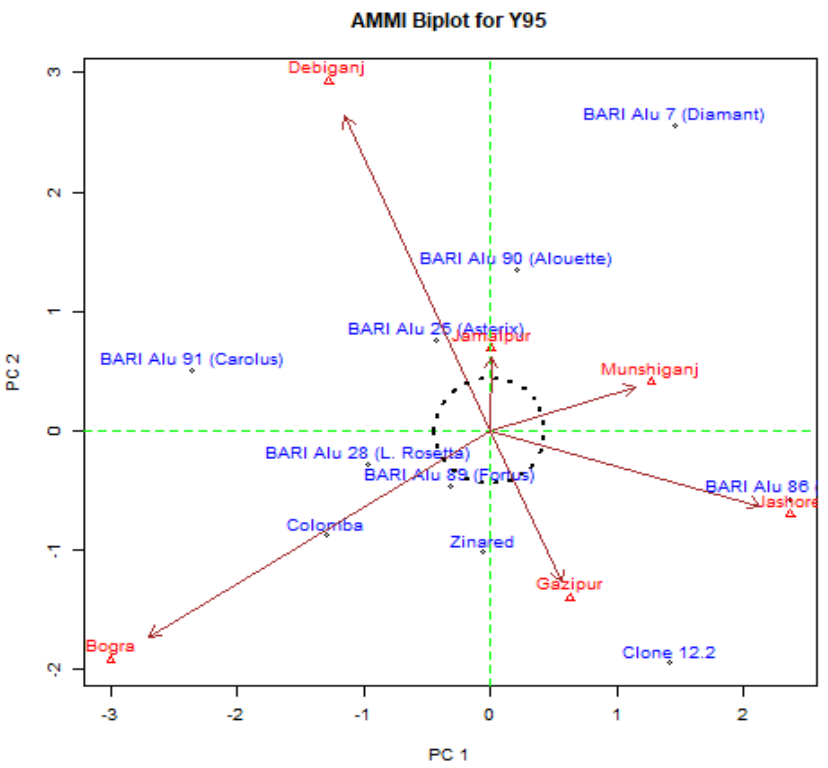

Fig 1: AMMI 1 Biplot for tuber yield (t/ha) of 10 potato genotypes and six environments using genotypic and environmental scores.

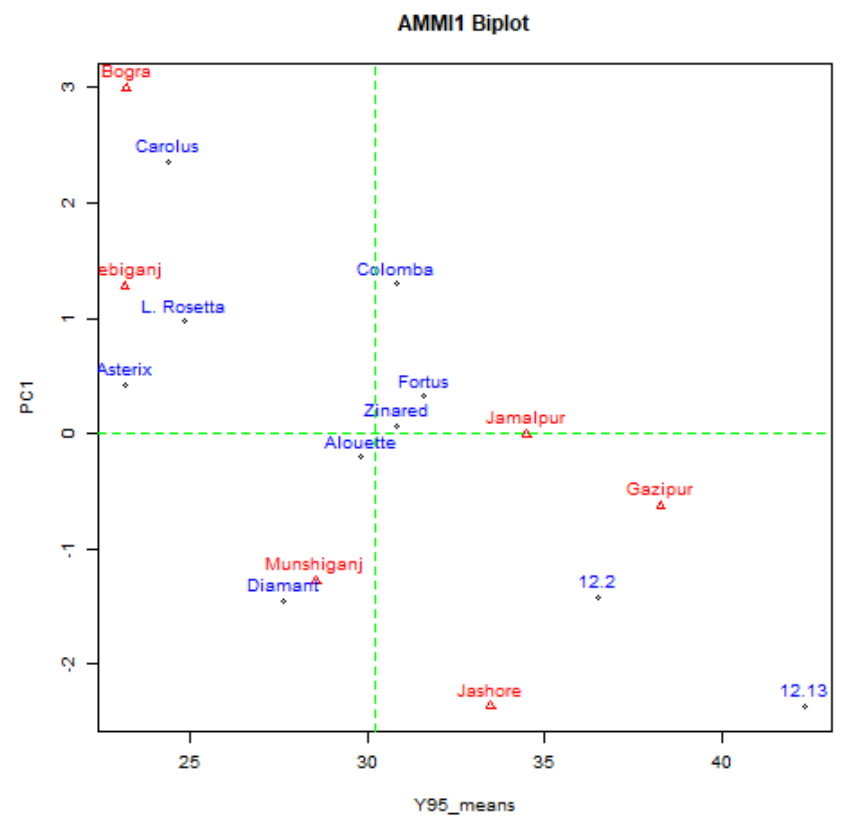

Fig 2: AMMI interaction (IPCA1) score plotted against mean tuber yield of potato genotypes. 
Tuber Yield and Stability Assessment of Potato Genotypes in Bangladesh

Table 3: Environment wise performance along with stability parameters for different characters in potato genotypes.

\begin{tabular}{|c|c|c|c|c|c|c|c|c|c|c|c|c|c|c|}
\hline \multirow{2}{*}{ Genotype } & \multicolumn{2}{|c|}{$\mathrm{PH}$} & \multicolumn{2}{|c|}{$\mathrm{SNH}$} & \multicolumn{2}{|c|}{$\mathrm{TNH}$} & \multicolumn{2}{|c|}{ Y65 } & \multicolumn{2}{|c|}{ Y90 } & \multicolumn{2}{|c|}{$\mathrm{DM}$} & \multicolumn{2}{|c|}{ TWH } \\
\hline & bi & $\mathrm{S}^{2} \mathrm{di}$ & bi & $\mathrm{S}^{2} \mathrm{di}$ & bi & $\mathrm{S}^{2} \mathrm{di}$ & bi & $\mathrm{S}^{2} \mathrm{di}$ & bi & $\mathrm{S}^{2} \mathrm{di}$ & bi & $\mathrm{S}^{2} \mathrm{di}$ & bi & $\mathrm{S}^{2} \mathrm{di}$ \\
\hline BARI Alu-7 (Diamant) & $0.613^{*}$ & 1.67 & 1.10 & 0.09 & 0.98 & 5.25 & 2.11 & 13.53 & 1.02 & 0.12 & $0.583^{*}$ & 0.27 & 1.65 & 0.01 \\
\hline BARI Alu-25 (Asterix) & 1.10 & 29.35 & 0.69 & 0.95 & 0.70 & 1.17 & 0.09 & 4.50 & 0.82 & 6.64 & 1.20 & 1.90 & 0.94 & 0.00 \\
\hline BARI Alu-28 (L. Rosetta) & 0.68 & 21.07 & $0.330^{*}$ & 4.32 & 0.98 & 0.25 & 0.30 & 0.91 & $0.511^{*}$ & 48.83 & 0.80 & 5.43 & $0.376^{*}$ & 0.01 \\
\hline BARI Alu-86 (12.13) & 2.07 & 256.39 & 1.41 & 1.63 & 1.27 & 1.27 & 0.11 & 3.45 & 1.80 & 129.02 & 1.30 & 0.47 & 1.84 & 0.02 \\
\hline BARI Alu-89 (Fortus) & 0.68 & 28.86 & 1.36 & 1.27 & 1.04 & 1.53 & 0.35 & 2.12 & 1.08 & 1.27 & 0.88 & 1.72 & 0.85 & 0.00 \\
\hline BARI Alu-90 (Alouette) & 0.78 & 24.56 & 1.24 & 0.57 & 1.27 & 1.68 & -1.70 & 8.47 & 0.92 & 1.32 & 0.41 & 2.03 & 1.09 & 0.00 \\
\hline BARI Alu-91 (Carolus) & 1.13 & 19.22 & 0.96 & 0.01 & 1.26 & 0.57 & -1.15 & 18.81 & 0.34 & 88.39 & 0.88 & 0.44 & 0.39 & 0.01 \\
\hline Colomba & 1.03 & 41.82 & 1.24 & 0.57 & 1.35 & 0.71 & -1.01 & 6.08 & 0.79 & 8.67 & 1.35 & 4.34 & 0.62 & 0.00 \\
\hline Zinared & 0.48 & -2.78 & 0.65 & 1.20 & 0.44 & 1.20 & 0.24 & 9.59 & 1.17 & 6.05 & 1.23 & 3.49 & 0.80 & 0.00 \\
\hline Clone 12.2 & 1.39 & 36.71 & 1.02 & 0.00 & 0.71 & 4.51 & -.14 & 4.60 & 1.54 & 60.37 & 1.26 & 4.90 & 1.44 & 0.01 \\
\hline
\end{tabular}

*Significant at the 0.05 probability level.

GGE Biplot for Y95

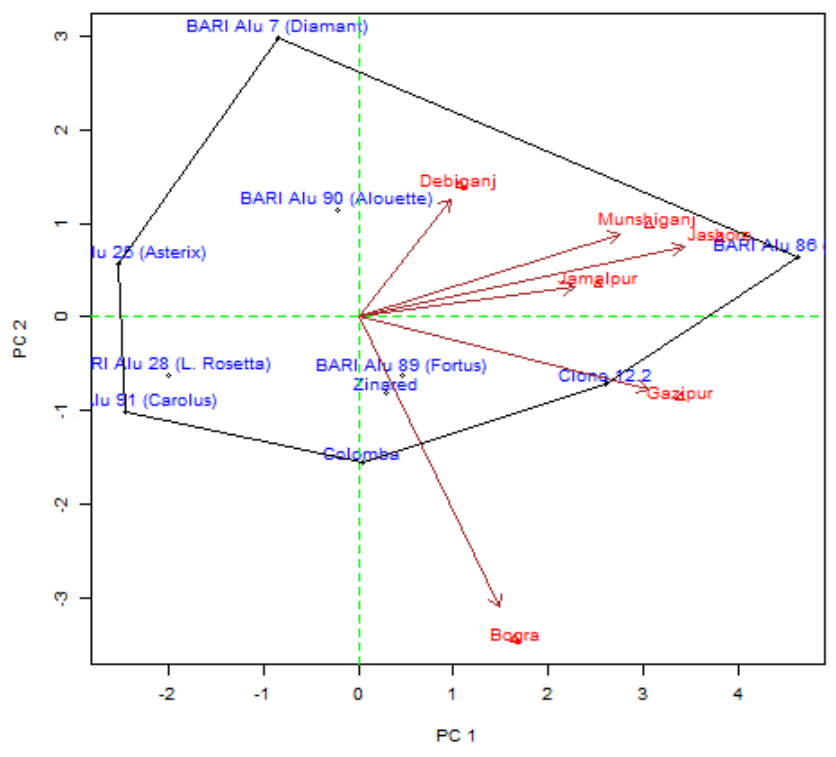

Fig 3: GGE biplot showing "which won where" for potato genotypes.

habit and leaf angle orientation and that of dry matter and starch content.

Stability of yield is likely to be aided by the consistent establishment of optimum stem densities. The bi value for $\mathrm{SNH}$ ranges from 0.33 to 1.41 . BARI Alu-28 had a relatively lower value of bi (0.33) which denoted less responsive to the environmental change (Table 3). The bi value for TWH ranges from 0.376 to 1.84 . BARI Alu-28 had a relatively lower value of bi. Genotypes with lower (close to 0 ) deviation from regression $\left(\mathrm{S}^{2} \mathrm{di}\right.$ ) value and high (above Average) mean efficiency are regarded as stable. Therefore varieties with stable relationships between the number of stems per tuber and tuber weight are likely to give more stable yields (Wurr and Morris, 1979). Further, tubers with high dry matter content that are suitable for processing factory. The source of variation in tuber dry matter production depended on cultivar and environment. The variation in tuber dry matter production and thus growth duration per cultivar could be related to the climate factors, day length and temperature. Breeding for high dry matter production at one location does not guarantee high dry matter production at other location. Late cultivars seemed to be more sensitive than the early cultivars (Kooman et al., 1996). The bi value for dry matter production ranges from 0.41 to 1.35 . BARI Alu-89 (Alouette) had the lowest bi value $(0.511)$ mean less responsive to the environmental change.

\section{CONCLUSION}

Tuber yields analysis using AMMI and GGE (genotype plus Genotype $\times$ Environment interaction) allowed us to find the best performing ideal varieties across locations. The BARI Alu-86 and clone 12.2 can be selected for commercial cultivation due to its higher tuber yield at final harvest. It is suggested to know the potato genotypes response to different environment over the years. This research was supported by The Tuber Crops Research Center, Bangladesh Agricultural Research Institute and funded by the NATP (phase 2, PBRG-BARC, ID 20) and USAID, Feed the Future Initiated, Award number BFS-G-11-00002.

\section{REFERENCES}

Cole, C.S. (1980). Potato tuber damage-breeder's problems. Annals of Applied Biology. 96(3):354-7.

de Haan, S. and Rodriguez, F. (2016). Potato Origin and Production. In: Advances in Potato Chemistry and Technology. Elsevier. pp. 1-32.

Eberhart, S.T., Russell, W.A. (1966). Stability parameters for comparing varieties 1. Crop Science. 6(1): 36-40.

Hijmans, R.J. (2003). The effect of climate change on global potato production. American Journal of Potato Research. 80(4): 271-9.

Houghland, G.V., Akeley, R.V., Kehr, A.E. (1961). A program for breeding industrial potato varieties. American Potato Journal. 38(12): 419-22.

Kooman, P., Fahem, M., Tegera, P. and Haverkort, A. (1996). Effects of climate on different potato genotypes 1. Radiation interception, total and tuber dry matter production. European Journal of Agronomy. 5: 193-205. 
Kumari, M., Kumar, M. and Solankey, S.S. (2018). Breeding Potato for Quality Improvement. Potato: From Incas to All Over the World. 37.

Lei, Y., Zhang, H., Chen, F., Zhang, L. (2016). How rural land use management facilitates drought risk adaptation in a changing climate-A case study in arid northern China. Sci. Total Environ. 550: 192-199.

Mahalingam, L., Mahendran, S., Chandra, R. and Atlin, G. (2006). AMMI analysis for stability of grain yield in rice (Oryza sativa L.). International Journal of Botany. 2: 104-106.

Munzert, M. (1987). Potato breeding strategy in the Federal Republic of Germany. The Production of New Potato Varieties: Technological Advances. 28: 38-44.

Purchase, J., Hatting, H. and Van Deventer, C. (2000). Genotype × environment interaction of winter wheat (Triticum aestivum L.) in South Africa: II. Stability analysis of yield performance. South African Journal of Plant and Soil. 17: 101-107.
Singh, K., Prasad, R.A., Chowdhury, S.L. (1976). Effect of nitrogen, phosphorus and rhizobium inoculation on growth and yield of pigeon pea under rainfed conditions (India). Indian Journal of Agronomy. 21: 49-53.

Wang, J., Zhang, Z. and Liu, Y. (2018). Spatial shifts in grain production increases in China and implications for food security. Land Use Policy. 74: 204-213.

Wurr, D. and Morris, G. (1979). Relationships between the number of stems produced by a potato seed tuber and its weight. The Journal of Agricultural Science. 93: 403-409.

Yan, W. and Kang, M.S. (2002). GGE Biplot Analysis: A Graphical Tool for Breeders, Geneticists and Agronomists. CRC press.

Yan, W., Kang, M.S., Ma, B., Woods, S. and Cornelius, P.L. (2007). GGE biplot vs. AMMI analysis of genotype-by-environment data. Crop Science. 47: 643-653. 